\title{
ARTÍCULOS
}

\section{9-1977. LA CONSTRUCCIÓN DE LA IMAGEN DE LA MONARQUÍA ESPAÑOLA A TRAVÉS DE LAS ENCUESTAS}

\author{
1969-1977. The construction of the image of the Spanish monarchy through \\ opinion polls
}

\author{
Raúl Magallón Rosa \\ Universidad Carlos III de Madrid \\ raul.magallon@uc3m.es \\ Orcid: 0000-0002-2236-7802
}

\section{Cómo citar este artículo/Citation:}

Raúl Magallón Rosa, "1969-1977. La construcción de la imagen de la monarquía española a través de las encuestas", Hispania Nova, 19 (2021): 421 a 448.

DOI: https://doi.org/10.20318/hn.2021.5887
Copyright: (c) HISPANIA NOVA es una revista debidamente registrada, con ISSN 1138-7319 y Depósito Legal M 9472-1998. Los textos publicados están -si no se indica lo contrario- bajo una licencia Reconocimiento-Sin obras derivadas 3.0 España de Creative Commons. Puede copiarlos, distribuirlos y comunicarlos públicamente siempre que cite su autor y la revista y la institución que los publica y no haga con ellos obras derivadas. La licencia completa se puede consultar en: http://creativecommons.org/licenses/by-nd/3.0/es/deed.es
Resumen: El objetivo de este estudio es analizar el papel de las encuestas censuradas y silenciadas en la transición española sobre Juan Carlos de Borbón y la monarquía española entre 1969 y 1977. En este trabajo se analizan las encuestas nunca hechas públicas por el Instituto de Opinión Pública -renombrado CIS en 1977- y Foessa, además de los estudios de opinión realizados a partir de 1976 por Gallup España. Lo que muestran los distintos sondeos es que ni siquiera una dictadura que ya duraba 30 años había conseguido el consenso social y cultural necesario para que legitimación social y legal fueran coincidentes.

Palabras clave: Transición, España, Monarquía, República, Encuestas.
Abstract: The aim of this study is to analyze the role of censored and silenced polls in the Spanish. This paper analyzes the opinión polls never made public by Foessa and the the Spanish Institute of Public Opinion - renamed CIS in 1977 -, in addition to the opinion studies carried out since 1976 by Gallup Spain. What the different polls showed was that not even a dictatorship that had lasted 30 years had achieved the social and cultural consensus needed to make social and legal legitimation match.

Keywords: Transition, Spain, Monarchy, Republic, Opinion polls. 


\section{INTRODUCCIÓN. LAS ENCUESTAS PROHIBIDAS DE LA TRANSICIÓN ${ }^{1}$}

El objetivo de este trabajo es analizar el papel de las encuestas realizadas, silenciadas y censuradas entre 1969 y 1977 sobre la monarquía y la figura de Juan Carlos de Borbón en España. Entre 1955 y 1972 están perfectamente documentadas hasta seis encuestas que demostraban que las preferencias de los españoles por el sistema de Gobierno que debía de sustituir a la dictadura franquista no tenían que coincidir con los intereses de los dirigentes de la época.

En esta investigación nos centramos en el periodo comprendido entre 1969 y 1977 por considerar que es el más importante a la hora de comprender el papel de las encuestas de opinión en la toma de decisiones políticas y estratégicas en torno a la (re)construcción mediática, política y social de la monarquía de Juan Carlos I de Borbón.

Para la realización de este estudio se han distinguido dos periodos:

1.- De 1969 a 1976, con la designación de Juan Carlos de Borbón como sucesor a título de Rey, la muerte de Franco y la coronación de Juan Carlos I como Rey².

2.- A partir de 1976, cuando tiene lugar el referéndum sobre la Ley para la Reforma Política y, poco a poco, la imagen del monarca va aceptándose social, política y culturalmente como el símbolo de consenso de la Cultura de la Transición.

Esta investigación se justifica porque hasta ahora se han realizado estudios de gran profundidad y análisis sobre el papel de la prensa en la construcción de la imagen de la monarquía como institución clave en la transición, pero no se ha descrito con el mismo detalle cómo esas encuestas - nunca conocidas hasta hace pocos años por la opinión pública- pudieron afectar a la toma de decisiones en torno a la estrategia mediática que se siguió para consolidar una monarquía parlamentaria en España (Magallón-Rosa, 2018).

\footnotetext{
1 Esta investigación forma parte del proyecto de investigación RTI2018-093599-B-I00 "Historia, memoria y sociedad digital. Nuevas formas de transmisión del pasado reciente: La transición a la democracia en España".

${ }^{2}$ Como recuerda Amando De Miguel el segundo informe de la Fundación FOESSA le fue encargado en abril de 1969, antes de la designación de Juan Carlos de Borbón como sucesor a título de Rey.
} 
La investigación se inicia después de la emisión en noviembre de 2016 de una entrevista inédita realizada por la periodista Victoria Prego en 1995 a Adolfo Suarez y emitida veintiún años después en el programa de televisión La Sexta Columna. A partir de la reproducción de las declaraciones del expresidente del Gobierno -no publicadas durante más de 20 años- periodistas, historiadores y políticos intentaron reformular las consecuencias de esta revelación sobre la Cultura de la Transición en el escenario actual (Gallego, 2008; Martínez, 2016). Del mismo modo, se han identificado una serie de acontecimientos mediáticos que pudieron ser relevantes para entender las respuestas demoscópicas que ofrecían los españoles sobre la monarquía y sobre Juan Carlos de Borbón en un contexto de incertidumbre.

Desde este punto de vista, la aprobación de la Ley para la Reforma Política en diciembre de 1976 -con un 94,4\% de votos favorables en el referéndum- supuso un punto de inflexión para la imagen y apoyo a la monarquía de Juan Carlos I de Borbón.

\section{Objetivos, hipótesis y metodología}

Gracias a los trabajos publicados hasta la fecha (De Miguel, 2009; Carpintero, 2010; Magallón-Rosa, 2018), sabemos que entre 1970 y 1976 se realizaron al menos cinco encuestas -perfectamente documentadas y censuradas o silenciadas en su momento- que preguntaban a los españoles por sus preferencias sobre el mejor sistema de Gobierno para España y sobre la monarquía ${ }^{3}$ :

1. (1970) Informe Foessa (Fomento de Estudios Sociales y Sociología Aplicada).

2. (1971) Instituto Opinión Pública, Estudio 1046

3. (1971) Instituto Opinión Pública, Estudio 1050.

4. (1972) Instituto Opinión Pública, Estudio 1054.

5. (1976) Inicio de la serie de encuestas de Gallup España para la Casa Real ${ }^{4}$.

Los objetivos de esta investigación son los siguientes:

\footnotetext{
3 Raúl Magallón, "Las encuestas prohibidas: Monarquía o República”. Bez.es, 16 de mayo de 2017, https://www.bez.es/355153603/Las-encuestas-prohibidas-Monarquia-o-Republica.html

${ }^{4}$ Esta es la única encuesta a la que no hemos tenido acceso documental de forma directa y completa.
} 
- Analizar posibles relaciones entre acontecimientos históricos, decisiones políticas y encuestas sobre la monarquía realizadas entre 1969 y 1977.

- Comprender parte del papel de las encuestas en la construcción de la imagen mediática y social de Juan Carlos de Borbón y de la monarquía parlamentaria.

- Describir y ponderar la complejidad del debate en torno a la cultura de la transición con datos documentales de la época (Baby, 2018).

El acceso directo a la documentación que se presenta en este trabajo permite plantear las siguientes hipótesis:

H1. El inicio de las primeras investigaciones demoscópicas en nuestro país fue utilizado por la clase política dirigente de la dictadura para tomar decisiones sobre la construcción de la imagen pública de Juan Carlos de Borbón.

H2. Un análisis y estudio de estas encuestas permite principalmente comprender la complejidad del escenario político y social en el que se desarrolló la transición.

Paralelamente -y como criterio metodológico- una vez analizadas las distintas encuestas disponibles sobre el periodo analizado, se ha optado por hacer una clasificación temporal que permita comprender mejor algunas decisiones que se pudieron tomar entonces.

Desde un punto de vista demoscópico, se ha realizado la siguiente tabla con las fechas más importantes para comprender los cambios de estrategia mediática y discursiva que se siguieron hasta conseguir que Juan Carlos de Borbón fuera aceptado en el imaginario de la mayoría de españoles:

\section{Tabla $n^{0}$ 1. Principales acontecimientos mediáticos}

\begin{tabular}{|l|l|}
\hline \multicolumn{1}{|c|}{ FECHA } & \multicolumn{1}{c|}{ ACONTECIMIENTO } \\
\hline 22 de julio 1969 & $\begin{array}{l}\text { Designación por las Cortes franquistas como sucesor } \\
\text { a título de Rey de Juan Carlos de Borbón. }\end{array}$ \\
\hline 8 de marzo de 1972 & $\begin{array}{l}\text { Boda de Alfonso de Borbón y María del Carmen } \\
\text { Martínez-Bordiú y Franco. }\end{array}$ \\
\hline $\begin{array}{l}\text { De 19 de julio al 2 de septiembre de 1974 y del } \\
30 \text { de octubre al 20 de noviembre de 1975 }\end{array}$ & $\begin{array}{l}\text { Interinidad asumida por Juan Carlos de Borbón de la } \\
\text { jefatura del Estado. }\end{array}$ \\
\hline 22 de noviembre de 1975 & $\begin{array}{l}\text { Proclamación como Rey de España de Juan Carlos de } \\
\text { Borbón. }\end{array}$ \\
\hline 15 de diciembre de 1976 & Referéndum sobre la Ley para la reforma política. \\
\hline 21 de enero de 1977 & $\begin{array}{l}\text { El Consejo de Ministros aprueba que Felipe de } \\
\text { Borbón ostente el título y la denominación de } \\
\text { Príncipe de Asturias. }\end{array}$ \\
\hline 14 de mayo de 1977 & Cesión de los derechos dinásticos de Juan de Borbón. \\
\hline
\end{tabular}

Fuente: Elaboración Propia 
La elección de estas fechas se explica por su importancia desde un punto de vista informativo y mediático a la hora de representar, radiografiar y comprender la evolución de la percepción social de los españoles sobre la figura de Juan Carlos de Borbón y la reinstauración de la monarquía. En un contexto político marcado por los cambios de una dictadura a una democracia, con problemas sociales y con la presión del terrorismo de ETA, las cuestiones relativas a la forma de Estado quedaron maquilladas y subordinadas a un plano discreto. En este sentido, resulta pertinente tener en consideración que en relación a la historiografía sobre la transición española a la democracia existe un debate acerca de los protagonismos en dicho proceso de cambio político (Seco, 1995; Zugasti, 2005; Velasco, 2018). En ese debate, los datos internos que se manejaron desde el régimen franquista pudieron ser determinantes para consolidar la monarquía en España.

\section{LOS INFORMES FOESSA. EL VALOR DE LOS DATOS PARA LA CONSTRUCCIÓN DE UN RELATO MEDIÁTICO-POLÍTICO}

Las encuestas, dependiendo del momento, tienen diferentes funciones políticas y de acción independientemente de que se realicen en estados democráticos o en dictaduras. En ocasiones son empleadas para reforzar las líneas editoriales de los medios y legitimar sus posiciones partidistas. Otras veces, la conversión de los sondeos en relatos noticiosos, la interpretación de los mismos y el análisis a través de la opinión fortalecen las relaciones de dependencia mutua entre medios de comunicación y política (Sánchez-Duarte y Magallón-Rosa, 2019). En cualquier caso, todas tienen en común que quien maneja esa información de manera exclusiva tiene la capacidad de anticiparse y crear estrategias predeterminadas.

La Fundación FOESSA (Fomento de Estudios Sociales y Sociología Aplicada) se constituyó en 1965 con el impulso de Cáritas Española. En 1966 y coincidiendo con la aprobación de la Ley 14/1966, de 18 de marzo, de Prensa e Imprenta 5 o "Ley Fraga" (donde se abolía la censura previa) se presentó el Informe sociológico sobre la situación

\footnotetext{
5 Ley 14/1966, de 18 de marzo, de Prensa e Imprenta. https://www.boe.es/buscar/act.php?id=BOE-A$\underline{1966-3501}$
} 
social de España. En abril de 1969, FOESSA encargaría al sociólogo Amando de Miguel el segundo informe. Éste se publicó en 1970 con el título: Informe sociológico sobre la situación social de España, 1970 y buscaba responder a las críticas del elaborado en 1966 en el que se intentaba hacer un diagnóstico de la situación social española prescindiendo del poder político. Como cuenta De Miguel (2009), el capítulo cinco fue censurado a última hora por orden expresa de Luis Carrero Blanco, entonces vicepresidente del gobierno. Como el libro ya estaba impreso, los 5.000 ejemplares fueron adquiridos por el gobierno de Franco para ser distribuidos entre los altos cargos del régimen.

En la reedición nadie se percató de que, aunque no aparecía ninguna página del capítulo, sí estaba la referencia en el índice bajo el título "Cap 5. Vida política y Asociativa". El hecho de que el nombre del capítulo apareciera en el índice -aunque hubiera sido censurado el texto- consiguió que la censura se hiciera más que visible y su huella más relevante. Como recuerda De Miguel (2009), “años después una parte de ese capítulo se tradujo al inglés y se incluyó en un volumen compilado por Stanley Payne”. En el año 2003, el capítulo completo se publicó como apéndice del libro El final del franquismo. Testimonio personal del propio Amando De Miguel.

A diferencia de las encuestas realizadas hasta ese momento que preguntaban por cuestiones políticas de manera indirecta, el análisis de 1970 supuso un paso más allá a la hora de conocer la opinión pública española. Entre otras cuestiones, se preguntaba si era posible una democracia sin partidos. El propio Amando de Miguel, recordando este informe en el artículo Historia personal de una desmesura: los "foessas" (2009), concluye: "Siempre tuve la sensación, con este trabajo y con otros, que los sociólogos somos realmente los cronistas de nuestra sociedad para que algún día la conozcan los historiadores del futuro".

Respecto al entonces inexistente debate público entre monarquía y república como sistema político preferido para los españoles -vacante el Jefe del Estado-, un 39\% de estudiantes de Bachillerato prefería mantenerse como hasta entonces -frente al $38 \%$ que apostaba por la república- y un $76 \%$ de los estudiantes universitarios prefería la república -frente al 11\% que prefería la monarquía borbónica-.

Por su parte, el 55\% de los abogados marcaba como primera opción la república frente a un $23 \%$ que señalaba la monarquía borbónica. Los médicos preferían la república en un $43 \%$-frente a la opción de mantenerse en el sistema de entonces que 
alcanzaba el 20\% de apoyos-. Entre los empleados, la primera opción era la república con el $45 \%$ de apoyo -frente al 37\% que prefería mantenerse con el mismo sistema de gobierno-. Por su parte, los obreros preferían mantenerse como hasta entonces en un $55 \%$-frente al $30 \%$ que se decantaba por la república-.

Por otra parte, el porcentaje de personas que no contestaba estaba entre el $6 \%$ para los estudiantes de Bachillerato y el 19\% para los distintos profesionales. En cualquier caso, era evidente el apoyo de los más jóvenes a la república.

\section{Imagen $n^{0}$ 1. Capítulo 5 del Informe Foessa}

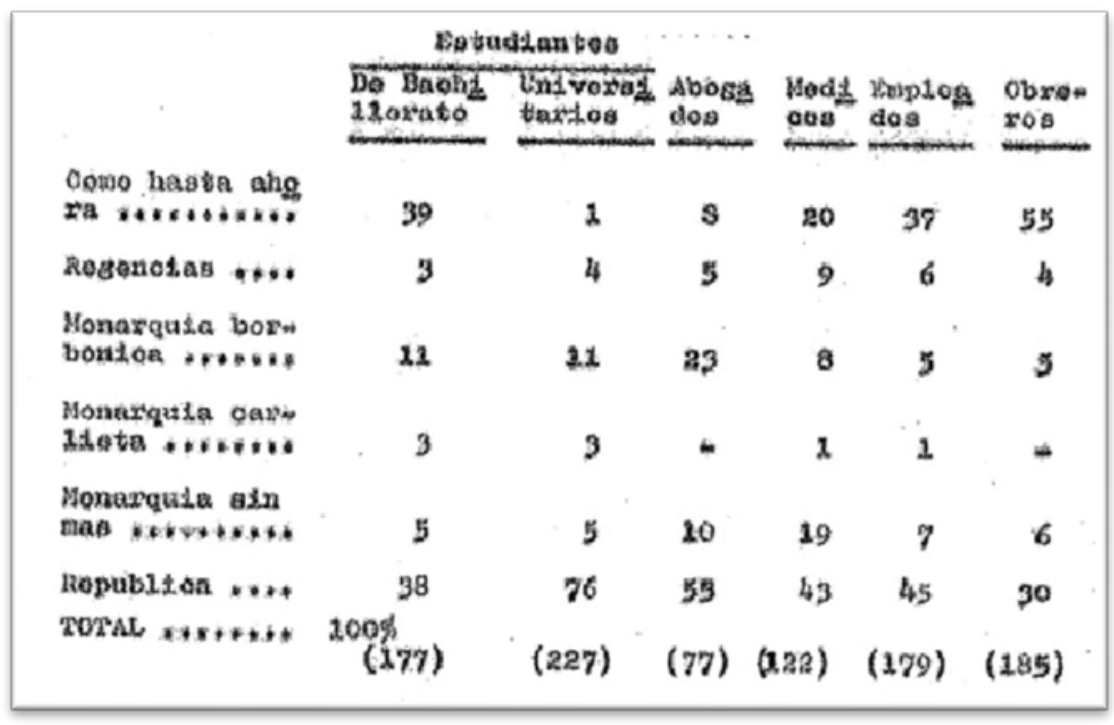

Fuente: Foessa, 1970

De esta encuesta se deduce también que la monarquía no era la primera elección entre ninguno de los grupos encuestados, a diferencia de la república que era opción preferente para universitarios, abogados, médicos y empleados.

\section{LA EVOLUCIÓN MEDIÁTICA Y SOCIAL DE LA FIGURA DE JUAN CARLOS DE BORBÓN}


Existen diferentes formas de aproximarse al estudio de la monarquía española durante la Transición, la más recurrente ha sido a través del papel de la prensa. Para Naftalí Paula (2019), las relaciones entre prensa y corona se pueden analizar desde dos perspectivas: por un lado, las obras que estudian el denominado pacto del silencio y la censura previa y, por otro, las que analizan el mencionado tabú periodístico en cuanto a las noticias referentes a la Corona. Desde esta perspectiva, Zugasti (2009) destaca que la designación de Juan Carlos de Borbón estuvo precedida por tres eventos importantes para el desenlace de la cuestión monárquica y que sirvieron para preparar el terreno al nombramiento:

- En primer lugar, el trigésimo cumpleaños del príncipe Juan Carlos de Borbón, celebrado el 5 de enero de 1968 (el interés radicaba en que el entonces príncipe cumplía la edad requerida por la Ley de Sucesión para ser nombrado sucesor).

- En segundo lugar, el bautizo del entonces infante Felipe de Borbón, que tuvo lugar el 8 de febrero de 1968.

- En tercer lugar, las declaraciones de Juan Carlos de Borbón al director de la agencia EFE, publicadas por primera vez el 7 de enero de 1969, en las que el entonces príncipe se mostraba partidario de ser nombrado sucesor sin respetar el orden dinástico.

Al respecto, hay que recordar que la Ley de Sucesión en la Jefatura del Estado de 1947 señalaba en su artículo noveno: "Para ejercer la Jefatura del Estado como Rey o Regente se requerirá ser varón y español, haber cumplido la edad de treinta años, profesar la religión católica, poseer las cualidades necesarias para el desempeño de su alta misión y jurar las Leyes fundamentales, así como lealtad a los principios que informan el Movimiento Nacional".

Ana María Velasco, sobre esta relación entre monarquía y prensa, señala que la llegada de la democracia supuso el fin de la censura y del control de los medios de comunicación. Y añade: "Sin embargo, se protegió especialmente a la corona y al soberano. El rey, que supuestamente solo tiene dimensión simbólica en el Estado, será un personaje clave en la Transición" (Velasco, 2018). Desde esta perspectiva, el pacto de silencio se mantuvo durante décadas. Carratalá (2014), defiende que "el discurso hegemónico, producido y difundido por los medios, ha otorgado una cobertura privilegiada a la institución. Mediante ese pacto tácito de complicidad, prensa, radio y televisión se han sometido a un tratamiento que combinaba dosis de amnesia con otras 
de tolerancia, ignorancia y aproximación benévola a aquellos aspectos más sensibles vinculados con la Casa Real".

En cualquier caso, tal y como recuerda Zugasti (2005: 141-168), “durante el período en que institucionalmente se completó la transición, los periódicos forjaron la imagen de Juan Carlos I que se ha mantenido hasta nuestros días, caracterizada fundamentalmente por el énfasis puesto en su papel como actor democratizador”.

\section{La proclamación de don Juan Carlos como Rey de España.}

\section{La estrategia de creación de una imagen pública}

Fernando Ramos (2013) señala que “el llamado 'imaginario monárquico` es una construcción simbólica que pretende introducir en la mente de los públicos la aceptación sin crítica de la monarquía como institución de carácter natural, que debe ser admitida como tal sin discusión posible”. Sin embargo, las encuestas de la época lo que nos muestran precisamente es la complejidad del escenario y la necesidad de establecer desde las instituciones decisorias una campaña mediática que transformara la imagen del entonces príncipe.

Zugasti (2005), por su parte, defiende que "la explicación 'personalista' de la transición ha recibido críticas que le achacan el haber creado unos hiperliderazgos con el fin de legitimar democráticamente a esas personalidades reformistas del franquismo, capitalizando a posteriori, una vez conocido el final feliz del proceso, la buena imagen social del éxito de la transición".

Frente al relato de la democratización (Prego, 1995) se encuentra -a veces en oposición, a veces como continuación- una narrativa de estabilidad. Al respecto, José Carlos Rueda (2013) señala que la retórica sobre la Monarquía del Movimiento se construyó como exégesis de las palabras de Franco, en particular de su intervención ante las Cortes del 22 de julio de 1969. En aquel discurso, el dictador había indicado que la instauración culminaba el proceso constitucional encarnado en las Leyes Fundamentales, que garantizaba la estabilidad y la continuidad, y acababa 'con las especulaciones internas`y 'los enredos políticos de determinados grupos`.

La Ley 62/1969, de 22 de julio, por la que se proveía lo concerniente a la sucesión en la Jefatura del Estado señalaba: 
Por todo ello, estimo llegado el momento de proponer a las Cortes Españolas como persona llamada en su día o sucederme, a título de Rey, al príncipe Don Juan Carlos de Borbón y Borbón, quien, tras haber recibido la adecuada formación para su alta misión y formar parte de los tres Ejércitos, ha dado pruebas fehacientes de su acendrado patriotismo y de su total identificación con los Principios del Movimiento y Leyes Fundamentales del Reino, y en el que concurren las demás condiciones establecidas en el artículo noveno de la Ley de Sucesión.

Encarnación Lemus (2008), desde esta perspectiva, destaca cómo se había construido un mensaje destinado a perdurar y del que arranca la interpretación de la Transición con Juan Carlos de Borbón pilotando el cambio. Este relato incluye además una nueva variable, las relaciones exteriores. Al respecto, Lemus apunta a que la influencia de la administración estadounidense puede detectarte desde, al menos, 1970 aunque no siempre halló la misma credibilidad. Con esta perspectiva, Paula (2019:85) subraya que "antes de acceder a la Jefatura del Estado, don Juan Carlos supo aprovechar estratégicamente la oportunidad de hablar en medios internacionales, dando pinceladas de su postura política y el camino que seguiría su reinado y la monarquía en España. Con ello tuvo la oportunidad de acercarse a Europa y a Estados Unidos”.

Es evidente que una estrategia de comunicación de cara al interior -pero también al exterior- necesitaba de los medios de comunicación para expandir el mensaje de "continuidad en el cambio". Desde este punto de vista, el discurso de proclamación de Juan Carlos de Borbón puede ser considerado un acontecimiento histórico y mediático excepcional, capaz de combinar ambas estrategias en torno a un momento y a una imagen que la historia había designado previamente como simbólica.

En este sentido hay que recordar que La ley 62/1969, de 22 de julio, por la que se proveía lo concerniente a la sucesión en la Jefatura del Estado señalaba en su artículo cuarto: "Vacante la Jefatura del Estado, el Príncipe Don Juan Carlos de Borbón y Borbón prestará juramento y será proclamado Rey por las Cortes Españolas, conforme al artículo séptimo de la Ley de Sucesión, y dentro del plazo de ocho días desde aquel en que se produzca la vacante".

Tras la muerte de Franco y con motivo del discurso ante las Cortes del recién proclamado Rey, el 22 de noviembre de 1975 Juan Carlos de Borbón inició su discurso señalando: "Yo sé bien que los españoles comprenden mis sentimientos en estos momentos. Pero el cumplimiento del deber está por encima de cualquier otra 
circunstancia. Esta norma, me la enseñó mi padre desde niño, y ha sido una constante de mi familia, que ha querido servir a España con todas sus fuerzas". Al respecto, Seco (1995) señala que los términos del discurso de don Juan Carlos en su proclamación ante las Cortes franquistas — 22 de noviembre de 1975-se podrían resumir en:

1. La apertura de España a todos los españoles ("La Institución que personifico integra a todos los españoles... os convoco porque a todos nos incumbe por igual el deber de servir a España");

2. La reconciliación nunca pretendida por Franco ("nuestro futuro se basará en un efectivo consenso de concordia nacional"');

3. El deseo de dar satisfacción a las reivindicaciones descentralizadoras ("El Rey quiere serlo de todos a un tiempo y de cada uno en su cultura, en su historia y en su tradición");

4. La promesa de libertades políticas siempre negadas hasta entonces ("Una sociedad libre y moderna requiere la participación de todos en los foros de decisión, en los diversos niveles educativos y en el control de la riqueza nacional. Hacer cada día más cierta y eficaz esta participación, debe ser una empresa comunitaria y una tarea de gobierno"). ${ }^{6}$

A partir de ese momento, el engranaje y la maquinaria de consenso irá legitimándose de manera creciente, aunque no automática. Al respecto, Sánchez-Prieto (1994) señala que:

La Transición se quiere y se presenta como un "presente histórico sin memoria histórica». Olvidar el pasado, un pasado sin historia (un pasado deformado por una conciencia histórica deformada, más bien), liberarse del pasado como preocupación -el mal de la España metafísica- era la mejor garantía para la reconciliación de los españoles y para la construcción de un horizonte de futuro; para la recuperación, en definitiva, de una España posible. Del pasado como preocupación al futuro como ocupación. De la España metafísica a una concepción pragmática de España.

En este sentido, parece plausible considerar que, con la estrategia del consenso, se tratara también de tranquilizar y garantizar el apoyo de las clases dominantes (Ortí, 1989). De hecho, la legitimación exterior como estrategia de consenso interior se reprodujo en los años siguientes incluso con mayor éxito. Ridao (2014) defiende que "con ser cierto que hubo presiones externas - como el Departamento de Estado

\footnotetext{
${ }^{6}$ Sin embargo, en el discurso no había una sola mención a la palabra democracia.
} 
estadounidense o la socialdemocracia alemana-, para evitar un desenlace como el de la Revolución de los Claveles en Portugal (1974), carece de cualquier base empírica verificable la tesis conspirativa global del diseño exterior de todo el proceso". La legitimación de la monarquía también fue acompañada de un ejercicio de ritualización de su imagen. Por esa razón, entre 1975 a 1978 los reyes desempeñaron una intensa actividad de representación que les llevó a realizar 28 viajes internacionales (Paula, 2019:100).

En consecuencia, parece obvio subrayar el consenso académico existente en torno a la idea de que la incipiente democracia tenía que salir del aislamiento internacional en el que había sumido el franquismo al país. En ese consenso, prevalecía la idea de que el Rey debía presentarse en el exterior e integrar España en el nuevo marco internacional.

Este relato adquiere una nueva dimensión tras la aprobación de la Ley para la Reforma Política. Es a partir de entonces donde los gestos simbólicos, políticos y jurídicos requieren de una mayor coordinación. Al respecto Zugasti (2007b) apunta a “que la aceptación del monarca fue efectiva el 21 de enero de 1977. A propuesta del presidente del gobierno, Adolfo Suárez, y previo acuerdo del Consejo de ministros, don Juan Carlos dispuso que su hijo don Felipe ostentara el título y la denominación de príncipe de Asturias, así como el resto de dignidades tradicionalmente usadas por el heredero de la Corona". Estos gestos fueron recogidos de manera más o menos uniforme y acrítica por la prensa.

Sin embargo, en un escenario de liberalización social y política, el papel de los medios necesitaba de una nueva estrategia. Fernando Ramos (2013) señala que una pieza esencial junto a las sucesivas leyes de la Reforma, fue el Real Decreto-Ley de 1 de abril de 1977 sobre la Libertad de Expresión, que derogaba el artículo 2 de la Ley de Prensa de Fraga, de 1966, pero que establecía que la administración podría decretar el secuestro de gráficos o documentos sonoros que contuvieran noticias, comentarios o información, en contra de la unidad de España, que constituyeran demérito o detrimento de la monarquía o que atentaran contra el prestigio de las Fuerzas Armadas ${ }^{7}$.

Desde esta perspectiva, y si consideramos que la tarea de Juan Carlos de Borbón durante la Transición fue precisamente obtener para su monarquía la legitimidad

\footnotetext{
${ }^{7}$ BOE, 12 de abril de 1977. https://www.boe.es/publicaciones/anuarios derecho/abrir_pdf.php?id=ANU$\underline{\mathrm{P}-1977-10020700210}$
} 
democrática a través de sus gestos y de sus acciones favorables a la liberalización del sistema político español, el nuevo escenario necesitaba un giro social que permitiera convertir su corona en liberal y ubicarla al margen de la dictadura franquista (Zugasti, 2007b).

Un giro, basado en la coordinación en torno a las diferentes estrategias que requería la nueva forma de Jefatura de Estado y el nuevo escenario político que estaba emergiendo.

\section{LA IMPORTANCIA DEL INSTITUTO DE OPINIÓN PÚBLICA EN LA CONSTRUCCIÓN MEDIÁTICA DE LA MONARQUÍA}

Poco a poco se va analizando con detalle la documentación generada por el Instituto de Opinión Pública -posteriormente renombrado en 1977 como Centro de Investigaciones Sociológicas, CIS- a la hora de describir y explicar algunas de las decisiones tomadas en España durante la Transición. Sin embargo, de esas encuestas no se supo nada hasta hace unos pocos años.

El 18 de noviembre de 2016, La Sexta Columna emitía una entrevista inédita de la periodista Victoria Prego al exPresidente del Gobierno Adolfo Suárez. Las declaraciones salían a la luz, en un programa especial, 21 años después de que tuviera lugar la entrevista ${ }^{8}$. Durante la misma y off the record, Adolfo Suárez -Presidente del Gobierno entre el 3 julio de 1976 y el 25 de febrero de 1981- confiesa a la periodista Victoria Prego que no sometieron a referéndum la monarquía porque las encuestas señalaban que lo perderían'. La propia Victoria Prego, entonces Presidenta de la Asociación de la Prensa de Madrid y adjunta al director en El Independiente, al día siguiente firmará un artículo publicado bajo el título "Una visita a la verdad del

\footnotetext{
${ }^{8}$ El primer presidente, en julio de 1963, del Instituto de Opinión Pública fue Luis Gónzalez Seara, posteriormente cofundador de Cambio 16 y Diario 16 y ministro de Universidades e Investigación con Adolfo Suárez.

9 “Así confesó Adolfo Suárez por qué no hubo referéndum monarquía o república: "Hacíamos encuestas y perdíamos", La Sexta, publicado el 18 de noviembre de 2016. https://www.lasexta.com/programas/sextacolumna/noticias/asi-confeso-adolfo-suarez-por-que-no-hubo-referendum-monarquia-o-republicahaciamos-encuestas-y-perdiamos 20161118582ef9fe0cf244336f09709f.html
} 
pasado"10. En el texto, señalaba: "Fue una de las muchas variables que la mente de Suárez manejaba como hipótesis y que le llevaron a encargar más de uno y más de dos sondeos de opinión porque necesitaba conocer, aunque fuera por encima, cómo pensaba el país desconocido -que no había hablado en los últimos 37 años- al que tenía que conducir por una senda de paz hacia la democracia".

Por su parte, Joan Garcés -Doctor en Ciencias Políticas-, afirmará en una entrevista a eldiario.es: "Lo que dice Adolfo Suárez está plenamente corroborado por los hechos. Que había encuestas antes de que muriera Franco y después es evidente. Algunas de ellas están publicadas y otras serían de acceso reservado a quienes las encargaban" $" 11$.

\section{La primera encuesta sobre la monarquía del Instituto de Opinión Pública (1971)}

En julio de 1971, sólo dos años después de la designación de Juan Carlos de Borbón como "sucesor, a título de Rey, del Jefe del Estado" el Instituto de Opinión Pública realizaría una encuesta bajo título "Encuesta mensual sobre cuestiones de actualidad política". El estudio se hizo a partir de 1000 entrevistas, 491 hombres y 509 mujeres (640 en Madrid y 360 en Barcelona) y, por supuesto, no fue publicado. Más allá de que sólo el $17 \%$ de las mujeres y el $28 \%$ de los hombres recordaran cómo se había llegado a esa designación, destaca que el 36\% respondió que esta designación resolvía el problema de la estabilidad política en España, el 18\% que sólo en parte, el 23\% que no lo resolvía y el 23\% no mostraba una opinión en público.

El estudio fue el primero de una serie de encuestas cuyas respuestas se utilizaron para conocer la imagen que proyectaba el entonces príncipe Juan Carlos de Borbón en los españoles y desarrollar una estrategia mediática y social que les permitiera ganar apoyos. La falta de memoria sobre la designación y la incertidumbre social y política necesitaban de datos demoscópicos para moldear la imagen del entonces príncipe.

\footnotetext{
${ }^{10}$ Victoria Prego, "Una visita a la verdad del pasado", El Independiente, 19 de noviembre de 2016, https://www.elindependiente.com/opinion/2016/11/19/una-visita-a-la-verdad-del-pasado/

11 Sofia Pérez Mendoza, "La monarquía actual tiene un origen ilegítimo", eldiario.es, 21 de noviembre de 2016 , https://www.eldiario.es/sociedad/ilegitimo-monarquia-debate-legitimidadGarces_0 582692490.html
} 
En este sentido, el 39\% de los encuestados respondió que las visitas y los viajes eran las actividades a las que se dedicaba con más frecuencia el entonces príncipe, mientras que sólo un $4 \%$ consideraban que fuera una actividad a la que debiera dedicarse más intensamente (eran respuestas que "el entrevistador debía anotar literalmente").

Del mismo modo, sólo el 9\% respondía que entre sus actividades más frecuentes estuviera el "tomar contacto con el pueblo", frente a un $27 \%$ que respondía que debería hacerlo más intensamente. Por el contrario, el 17\% respondía que entre sus actividades más frecuentes estaba el deporte. Sin embargo, no llegaron al 1\% las respuestas que afirmaran que debería hacerlo más intensamente.

\section{Imagen $\mathbf{n}^{0}$ 2. Actividades frecuentes del Príncipe Juan Carlos}

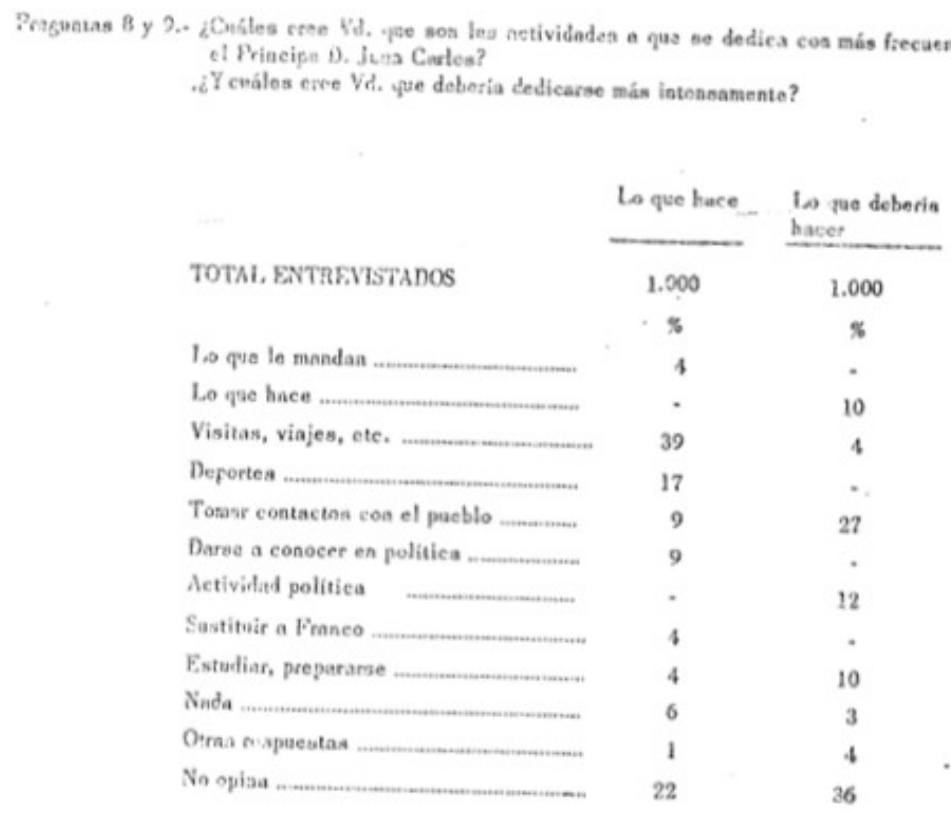

Fuente: Instituto de Opinión Pública

Cuando les preguntaban a los encuestados que completasen la frase, con lo primero que buenamente se les ocurriera, "La Monarquía va a significar para España...": el 18\% respondía que la continuidad del Régimen, el 12\% estabilidad, seguridad y paz, un 5\% un desastre, un fracaso, lo peor, el 3\% un avance, un paso hacia adelante, un $8 \%$ enfrentamiento entre opiniones, un $6 \%$ un paso atrás, un 3\% no 
va a significar nada, el 2\% el pueblo no es monárquico, el 5\% un periodo de transición (incertidumbre), un 5\% un bien para España y un 33\% no mostraba su opinión.

El conocimiento de esta realidad por parte de la dictadura franquista -más allá de un posible apoyo social a la monarquía o a la república- permitió establecer una estrategia para que los medios de comunicación -públicos y privados- engranaran su función social de 'consenso` de manera más eficaz, sentando al futuro Rey de España en los hogares de los españoles 'como un miembro más de la familia`.

\section{El monográfico del Instituto de Opinión Pública sobre la monarquía}

En noviembre de 1971 el régimen decidió realizar una encuesta con un bloque de diecisiete preguntas dedicadas en exclusiva a la figura del entonces príncipe y de la monarquía. Esto ocurría solo unos meses después de que el Instituto de Opinión Pública preguntara por primera vez por la designación de Juan Carlos de Borbón como "sucesor, a título de Rey, del Jefe del Estado". El intervalo tan breve de tiempo entre estas dos encuestas es significativo sobre todo si se tiene en cuenta que el Instituto de Opinión Pública había nacido en julio de 1963 y en esos ocho años nunca se había preguntado sobre la monarquía.

La primera encuesta realizada sólo cuatro meses antes posiblemente no tuvo las respuestas esperadas por la dictadura. Ante la pregunta abierta "La Monarquía va a significar para España...”, el 12\% había respondido que iba a significar estabilidad, seguridad y paz, sólo un 5\% respondió que un bien para España y tan sólo el 3\% respondió que un avance, un paso hacia adelante. Sin embargo, desde un punto de vista estratégico, la utilidad fue indudable para integrar al entonces príncipe Juan Carlos de Borbón en los salones de los españoles y moldear su imagen ante la opinión pública. Si en julio de 1971, sólo el 22\% recordaba cuándo había sido designado sucesor, en noviembre de 1971 la cifra alcanzaba el 32\%. Sin embargo, la respuesta de los entrevistados que sabían cómo se había producido la designación se mantenía en un $22 \%$.

Ante la pregunta: "Considera usted muy importante, simplemente importante, o más bien poco importante esta designación para el futuro de España”, del 28\% que había respondido que muy importante en julio de 1971 se pasaba al 32\% en noviembre y 
del $43 \%$ que lo habían considerado simplemente importante al $47 \%$ en cuatro meses. Si en julio de 1971 el 36\% creía que esta designación resolvía el problema de la estabilidad política española, en noviembre el $51 \%$ de los entrevistados respondía que la designación iba a ser beneficiosa para los españoles. Es importante subrayar que la formulación de la pregunta orientaba la respuesta y no es lo mismo hablar de "resolver un problema de estabilidad" que preguntar si algo será "beneficioso".

A partir de esta pregunta, los dos cuestionarios llevan caminos diferentes. Si el de julio de 1971 daba más opciones para que los entrevistados respondieran de manera espontánea, en el de noviembre las preguntas -cerradas y orientadas-, estaban determinando las propias respuestas.

\section{Tabla $n^{0}$ 2. Afirmaciones sobre la monarquía}

\begin{tabular}{llll}
\hline AFIRMACIONES SOBRE MONARQUÍA & JUL-71 & NOV-71 & DIFERENCIA \\
\hline Asegura la transmisión del poder político & $42 \%$ & $29 \%$ & $-13 \%$ \\
Impide la llegada al Poder de los más capacitados & $32 \%$ & $15 \%$ & $-17 \%$ \\
Es una institución de origen divino & $15 \%$ & $5 \%$ & $-10 \%$ \\
Es algo superado hace tiempo & $36 \%$ & $15 \%$ & $-21 \%$ \\
Garantiza el orden y la estabilidad & $40 \%$ & $25 \%$ & $-15 \%$ \\
Es un Gobierno a merced de los partidos políticos & $19 \%$ & $5 \%$ & $-14 \%$ \\
Está enraizada en la tradición e historia españolas & $54 \%$ & $30 \%$ & $-24 \%$ \\
El pueblo desea poder elegir a sus gobernantes & $59 \%$ & $34 \%$ & $-25 \%$ \\
Es un elemento equilibrador de los intereses en los & $29 \%$ & $14 \%$ & $-15 \%$ \\
distintos grupos sociales & & & $-8 \%$ \\
Todo depende de cómo sea el rey & $59 \%$ & $51 \%$ & \\
\hline
\end{tabular}

Fuente: Elaboración propia a partir de los datos ofrecidos por el IOP.

En el cuestionario de noviembre de 1971, también se incorporaron nuevas preguntas para conocer las preferencias de los españoles sobre cómo preferían recibir las informaciones relacionadas con el entonces príncipe (a través de la radio, la televisión, las revistas o los periódicos) así como preguntas relacionadas con la percepción de los españoles sobre el interés de Juan Carlos de Borbón hacia problemas como la educación, el desarrollo industrial, el campo o la emigración. 
Del mismo modo, el 58\% respondió que cuando Juan Carlos de Borbón ocupara el trono no habría cambios políticos importantes y sólo el $24 \%$ creía que mejorarían las cosas.

Por último, y entre las tres opciones que podían elegir los encuestados, las principales afirmaciones que la gente solía hacer cuando se hablaba de monarquía eran: “depende de cómo sea el rey", "el pueblo desea poder elegir a sus gobernantes y", en tercer lugar, "está enraizada en la tradición e historia española".

Tabla $n^{0}$ 3. Principales afirmaciones que la gente hace cuando se habla de monarquía

\begin{tabular}{|l|l|}
\hline Depende de cómo sea el Rey & $51 \%$ \\
\hline El pueblo desea elegir a sus gobernantes & $34 \%$ \\
\hline $\begin{array}{l}\text { La monarquía es una institución enraizada en la } \\
\text { tradición }\end{array}$ & $30 \%$ \\
\hline
\end{tabular}

Fuente: IOP. Noviembre de 1971.

El 51\% respondió “depende de cómo sea el rey”, el 34\% "el pueblo desea elegir a los gobernantes" y el 30\% que la monarquía era "una institución enraizada en la tradición". Nuevamente la complejidad del escenario se veía refrendado por los resultados demoscópicos.

\section{La boda de Alfonso de Borbón y Carmen Martínez de Bordiú}

En enero de 1972 el Instituto de Opinión Pública iniciaría un estudio con el título "Sondeo sobre la boda del Príncipe Alfonso de Borbón y María del Carmen Martínez de Bordiú” -el 23 de diciembre de 1971 se había efectuado la petición de mano de la nieta del dictador Francisco Franco y la boda se celebró el 8 de marzo de 1972-. Se trata de una encuesta de la que aún hoy se niegan tener resultados (Alcobendas, 2006). En el cuestionario se les recordaba a los encuestados que "su designación había sido debida al azar y sus opiniones individuales no serían conocidas por nadie". En la pregunta 5 , se indagaba sobre quién podría beneficiarse más de la boda. 
Imagen no 3. Pregunta 5 del sondeo sobre la boda del Príncipe Alfonso de Borbón y María del Carmen Martínez de Bordiú

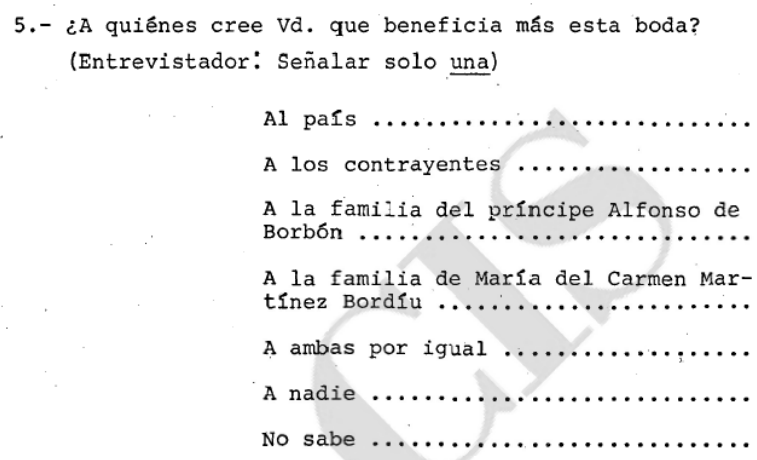

Fuente: Instituto de Opinión Pública. Estudio 1054. (1972)

En la pregunta 7 del cuestionario se señalaba: "De las frases que le voy a citar a continuación, - ¿Cuál cree Vd. que se identifica mejor con las posibles consecuencias de la boda?". Y las posibles respuestas eran:

\section{María del Carmen Martínez de Bordiú

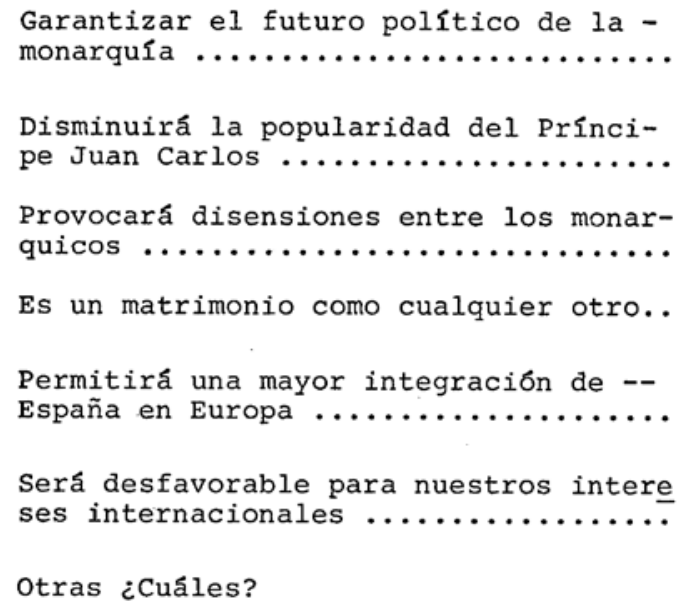

Imagen 4. Pregunta 7 del sondeo sobre la boda del Príncipe Alfonso de Borbón y

Fuente: Instituto de Opinión Pública. (1972)

Aunque evidentemente las preguntas más problemáticas eran la doce y la trece. La pregunta doce señalaba: “¿Piensa usted que el príncipe Alfonso de Borbón por su condición de nieto mayor de Alfonso XIII puede alegar ciertos derechos a la corona en el orden de sucesión?". 


\section{Imagen $n^{0}$ 5. Pregunta 12 del sondeo sobre la boda del Príncipe Alfonso de Borbón y María del Carmen Martínez de Bordiú

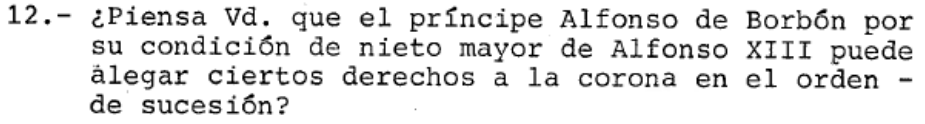

Fuente: Instituto de Opinión Pública. (1972)

Mientras que la pregunta trece estaba formulada de la siguiente manera: "Como Usted sabe para suceder al Jefe del Estado a título de rey se exigen una serie de requisitos (...) ¿Cree usted que el príncipe Alfonso de Borbón los reúne?”.

Ante las consecuencias que tuvo el conocimiento de su realización y las preguntas que cuestionaban directamente el futuro de la monarquía de Juan Carlos I, el sondeo fue suspendido. En la documentación guardada se señala que "por razones totalmente ajenas al I.O.P. el trabajo de campo hubo de ser suspendido, quedando reducida y alterada la muestra proyectada, tanto en el número total de entrevistas, cuanto en su distribución por distritos, sexo y edad".

La encuesta se realizó bajo la dirección de Juan Ramón Cercós Bolaños. Al respecto, cuenta María Pilar Alcobendas en su libro Historia del Instituto de Opinión Pública. 1963-1977 que "el sondeo no pasó inadvertido. A los pocos días de iniciarse el trabajo de campo, el debate sobre la Monarquía y el futuro monárquico era principal entre la clase política" (Alcobendas, 2006). El 18 de enero de 1972 -menos de un mes después del anuncio de boda- aparecería una nota de la agencia Europa Press en el diario Pueblo que señalaba que Cercós había presentado su dimisión. 


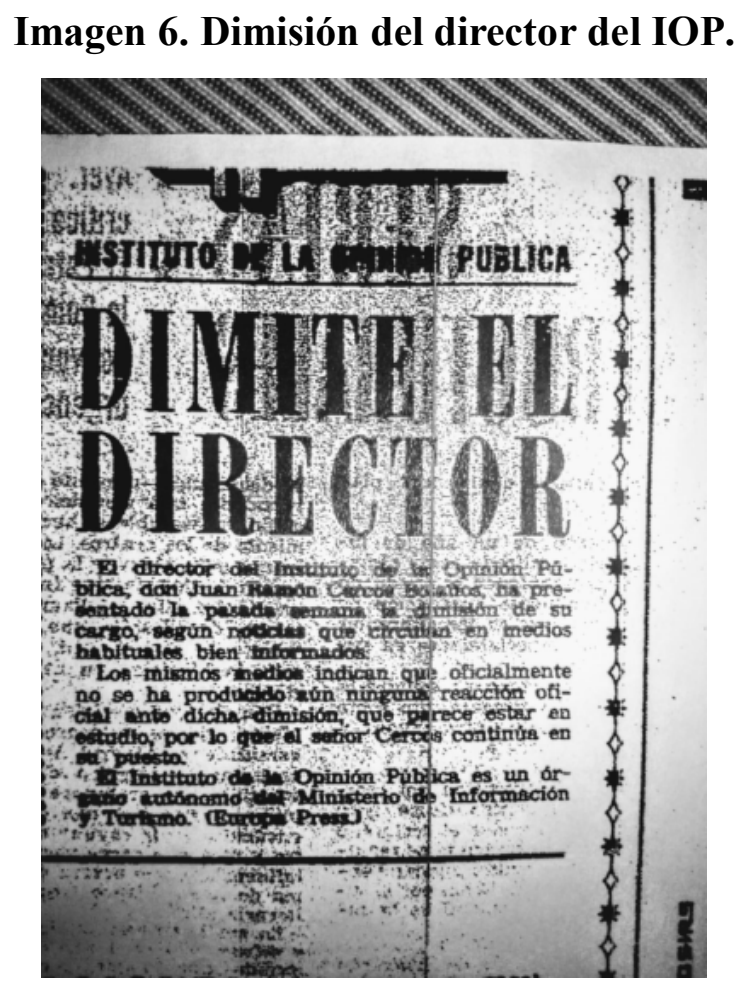

Fuente: Pueblo, 18 de enero de 1972.

Más allá de las respuestas -completas o incompletas-, lo más importante de esta encuesta es que las preguntas que se formulaban estaban planteadas de forma suficientemente clara como para considerar a Alfonso de Borbón como una opción legítima -al menos demoscópica y socialmente- para suceder al dictador Francisco Franco como Jefe de Estado.

\section{EL PAPEL DE GALLUP EN LA CREACIÓN DE LA IMAGEN DE CONSENSO DE LA MONARQUÍA}

La estrategia interna de legitimación de la monarquía se desarrolló en diferentes fases y con diferentes destinatarios. Al respecto, Naftalí Paula (2019: 90) señala:

Este cambio empezó a gestarse con la puesta en marcha de una campaña de imagen destinada a mejorar la comunicación del monarca. Parte de esta campaña se orientó a que los reyes viajaran de región en región sumergiéndose en baños de masas y acercándose 
a la población. En la prensa y la televisión primó el discurso que les definía como unos jóvenes simpáticos y accesibles, que estaban dispuestos a romper el protocolo para acercarse a la multitud, algo que se trasladó hasta nuestros días.

La combinación de una ritualización de la imagen externa e interna llevó diferentes tácticas y estrategias. Zugasti (2005), al respecto, defiende que "a partir de estos primeros momentos tras la muerte de Franco, la vinculación entre la Monarquía de Juan Carlos I y la legitimidad del 18 de julio que la hizo posible desapareció de la prensa, con la excepción de El Alcázar". En este sentido, el papel de la prensa extranjera tuvo especial relevancia durante el primer año y medio de la Transición, hasta las elecciones del 15 de junio de 1977, debido a la persistencia del control gubernamental sobre la prensa española y al compromiso de los periódicos españoles con el proceso de cambio político (Guillamet, 2015).

Sin embargo, estos nuevos tiempos necesitaron de nuevas formas de legitimación de la monarquía, pero también de nuevos mecanismos de deliberación y decisión internos. Desde esta perspectiva, ahora sabemos que entre 1976 y 1993 se realizaron, al menos, 41 encuestas destinadas a conocer la opinión de los españoles sobre la monarquía y sobre la imagen de Juan Carlos de Borbón como Rey. Las encuestas fueron realizadas por la empresa demoscópica Gallup y dirigidas por Jorge Miquel Calatayud, fundador y presidente de Gallup España entre 1976 y 1993.

La serie de estudios de opinión se inició en octubre de 1976, en plena Transición y, como reconoció el propio Miquel en un texto publicado en 2017, tenía dos objetivos: "por un lado intentaba medir la popularidad del Rey Juan Carlos y por otro indagaba sobre la aceptación popular de la Monarquía en España" (Miquel, 2017) ${ }^{12}$.

La segunda pregunta de esa primera encuesta, pese a la ambigüedad con la que fue formulada, sirve para completar los distintos estudios sobre la cuestión que había realizado anteriormente el Instituto de Opinión Pública -que, recordemos, pasaría a denominarse CIS en 1977-.

La pregunta clave de la encuesta de octubre de 1976 estaba redactada en los siguientes términos: "La existencia de una Monarquía en España para algunos es un hecho ya aceptado. Otros piensan que sería necesario someterla democráticamente a

\footnotetext{
12 Es importante destacar que entre 1976 y 1979 la muestra de las encuestas fue de 2.000 personas, reduciéndose a 1.000 personas a partir de marzo de 1980 .
} 
consulta en un Referéndum. ¿Con cuál de las dos opiniones se muestra usted más de acuerdo?".

\section{Imagen $n^{0}$ 7. Encuesta de octubre 1976 de Gallup.}

PREGUNTA 2: "La existencia de una Monarquía en España para algunos es un hecho ya aceptado.
Otros piensan que sería necesario someterla democráticamente a consulta en un
Referendum. ¿Con cuál de las dos opiniones se muestra usted más de acuerdo?"

\begin{tabular}{ccc} 
Hecho Aceptado & No & NC \\
& Descontentos & \\
\hline $40 \%$ & $38 \%$ & $22 \%$
\end{tabular}

Fuente: Jorge Miquel (2017).

A pesar de la formulación orientada de la pregunta (por los tiempos verbales y por el orden de las frases; además de que -por supuesto- no incluyera la palabra república), el 38\% respondió que sería necesario someter democráticamente a la monarquía en España a consulta en un referéndum, frente al $40 \%$ que respondió que la existencia de una monarquía en España era un hecho ya aceptado y a un $22 \%$ que no respondió.

Un análisis de estas respuestas nos permite comprender que, ya entonces, los españoles hacían una triple distinción: la de una buena imagen pública de Juan Carlos de Borbón frente a la monarquía como institución, la de distinguir entre aquellos que declarándose monárquicos consideraban que se debería hacer un referéndum para legitimar la monarquía en un sistema democrático y la de aquellos que deseaban votar a favor de la república.

Para completar los datos de la primera encuesta, Gallup decidió hacer varios grupos de discusión con aquellas personas que habían respondido a favor del referéndum. Según Miquel, las conclusiones de este estudio cualitativo mostraron que la mitad de los que se pronunciaban a favor del referéndum apoyaban la monarquía.

La diferencia tan pequeña entre las posiciones que consideraban la monarquía como hecho aceptado y las respuestas a favor de un referéndum, se mantuvieron en los diferentes estudios demoscópicos realizados hasta 1981. Desde entonces, y tras el golpe de estado del 23-F, el número de respuestas que consideraban que la monarquía era un hecho aceptado fue distanciándose cada vez más de las opiniones a favor del referéndum. 
En una entrevista publicada por El Mundo en 2016, el propio Jorge Miquel reconocía que esas encuestas eran más que conocidas por Juan Carlos de Borbón. Miquel afirmó entonces: "Nos reuníamos cada dos meses y le mantenía al día"13. El reconocimiento de su existencia, más de 40 años después de que empezaran a realizarse, demuestran que la frontera entre política e historia ya era lo suficientemente clara como para poder dar un testimonio relevante pero no comprometido en tiempos de revisitación histórica.

\section{CONCLUSIONES, DISCUSIÓN Y PERSPECTIVAS DE FUTURO}

Es evidente que la reconstrucción jerarquizada y estructurada de la historia de la Transición queda determinada por los nuevos materiales audiovisuales que puedan ir apareciendo (Magallón-Rosa, 2017). Al mismo tiempo, reaparece la importancia de desclasificar los documentos oficiales (incluidas grabaciones de audio y vídeo).

En cualquier caso, donde parece que existe un consenso es en la idea de que la apertura de la prensa española a partir de 1966 permitió a ésta desarrollar posteriormente un papel relevante en el intenso debate público de los primeros años de la Transición a la democracia (Zugasti, 2008).

Más allá de este consenso, el papel de la figura de Juan Carlos I en la Transición sigue siendo objeto de debate. Como apunta Seco (1995):

Franco no llegó a intuir nunca la profunda identificación entre el padre y el hijo en lo esencial: la convicción de que la Monarquía debia significar la paz efectiva tras una guerra civil nunca cerrada; la apertura de España a todos los españoles, lo que ya a esas alturas suponía una alternativa democrática, como contrapunto de la democracia traicionada de 1931.

Por su parte, Ortí (1989) hablará de un pacto interélites para evitar la ruptura social, afirmando que la primera Transición -que sitúa entre 1975 y 1981 - se fraguó a partir de un desencanto programado de las masas. Al respecto, parece pertinente recordar que tras la muerte de Franco y durante los primeros días de reinado, la prensa destacó mayoritariamente la ligazón del nuevo Rey con el anterior Jefe del Estado y con

\footnotetext{
${ }^{13}$ Véase: https://www.elmundo.es/espana/2016/08/16/57b21203468aebf3328b45dc.html
} 
la legitimidad franquista de la monarquía instaurada. Sin embargo, las cabeceras pasaron pronto de ser condescendientes con el franquismo a enjuiciar muy negativamente algunos de sus aspectos en contraste con la actuación de Juan Carlos I (Zugasti, 2005).

En este sentido, y como hemos visto, la evolución de la imagen de la monarquía estaba acompañada por la evolución de las estrategias de comunicación que se estaban desarrollando. Por una parte, unidireccionalidad en los mensajes sobre la corona; por la otra, control de los mensajes que salían de los medios de comunicación. Ambas fueron las fórmulas de institucionalización de una monarquía que necesitó de diferentes formas de persuasión para alcanzar sus objetivos.

Este distanciamiento se acentuó y modeló con el paso de los años. Desde esta perspectiva, es importante recordar que "Juan Carlos I pasa a comunicarse directamente con la ciudadanía a través de sus tradicionales discursos navideños de Televisión Española y las informaciones vinculadas a la Casa Real son transmitidas por los medios de forma consensuada con Zarzuela. Se sabe poco de la realeza y su inviolabilidad hace que se mantengan en secreto las cuestiones más inquietantes" (Velasco, 2018).

Este tipo de relación se mantendría, hasta volverse casi mecánica, con el paso de los años y sólo sería redefinida tras la aparición de nuevos medios digitales a principios de la segunda década del siglo XXI. Ramos, en este sentido, señalaba en 2012 que "los medios de comunicación, en su conjunto, parecen haber superado el pacto tácito de amnesia o silencio en torno a las cuestiones de la Casa Real que ha sido la tónica durante los años de reinado del sucesor del Caudillo a título de Rey" (Ramos, 2012). Sin embargo, en la actualidad, el principal problema discursivo para la historiografía es el de afrontar aquella revisitación del discurso histórico de la Transición que pretende establecer analogías para la argumentación dialéctica en torno a una Segunda Transición.

Como hemos afirmado anteriormente, el desafío social y mediático de la academia en este momento está precisamente en que no se utilice la Transición de manera maniqueísta entre los partidos políticos como una forma de causalidad irreversible que se puede repetir bajo los mismos objetivos y resultados de entonces.

Como hemos visto, la historia y el estudio de la transición monárquica puede establecerse sobre tres ejes: los acontecimientos históricos que marcaron el devenir de los hechos, las declaraciones públicas de los actores políticos que pretendían influir en 
el desarrollo de los acontecimientos y las propias encuestas internas sobre la monarquía que marcaban de manera invisible los dos primeros.

Más allá del silencio y censura que las acompañan, estas encuestas sólo dejaban claro una cosa: que los sondeos de opinión permitieron establecer las estrategias de comunicación necesarias para invitar a entrar en los hogares de los españoles -a través de la televisión- al futuro Rey de España.

El conocimiento de la realidad ofrecida por las encuestas para, primero, la dictadura franquista, y después para los actores protagonistas de la Transición resultó fundamental a la hora establecer estrategias diferentes -no sólo mediáticas, sino también económicas, políticas y sociales- de las que podrían haber seguido en el caso de haberse hecho públicas.

En este escenario, y más allá de un posible apoyo social a la monarquía o a la república, su realización permitió establecer una estrategia para que los medios de comunicación -públicos y privados- engranaran su función social de 'consenso'en diferentes fases y con distintas tácticas.

Por otra parte, hay un debate dialéctico entre los historiadores que puede tener puentes de diálogo. La apertura de datos y archivos debería servir para no simplificar el debate de la Transición española entre aquellos que consideran que el papel de Juan Carlos de Borbón fue el de continuador de la dictadura franquista, piloto de cambio o un actor con sus propias estrategias e intereses dentro de ese escenario de incertidumbre.

Más allá de los resultados de esas encuestas, la importancia de su existencia y de que sean publicadas reside precisamente en que fueran un secreto no revelado durante más de 40 años.

\section{BIBLIOGRAFÍA}

Alcobendas, María Pilar. IOP. Historia del Instituto de la Opinión Pública.1963-1977. Madrid: Centro de Investigaciones Sociológicas, 2006.

Baby, Sophie. El mito de la transición pacífica: violencia y politica en España (19751982). Madrid: Akal, 2018.

Carpintero, Heliodoro (2010). "Psicología y Política en España: La Encuesta de Pinillos de 1955". Psychologia Latina, 1, 2 (2010): 88-96. http://psicologia.ucm.es/data/cont/docs/29-2013-04-25-art6.pdf

Carratalá, Adolfo. "El tratamiento de la Monarquía española en las viñetas de los medios digitales". Revista Dígitos, 1 (2015): 127-154. https://revistadigitos.com/index.php/digitos/article/view/7 
De Miguel, Amando. II Informe Foessa. Informe sociológico sobre la situación social de España. Madrid: Fomento de Estudios Sociales y Sociología Aplicada, 1970.

--. Dos generaciones de jóvenes 1960-1998. Madrid: Edición Injuve, 2000.

--. El final del franquismo. Testimonio personal. Madrid: Marcial Pons Historia, 2003.

--. "Historia personal de una desmesura: los 'foessas"”. Politica y Sociedad, Vol. 46, Núm. $\quad 3$ (2009): 91-102. http://revistas.ucm.es/index.php/POSO/article/view/POSO0909230091A/21769

Gallego, Ferrán. El mito de la transición. La crisis del franquismo y los orígenes de la democracia (1973-1977). Barcelona: Crítica, 2008.

Guillamet, Jaume. "El regreso de la monarquía y la transición a la democracia en España (1975-78). Los apoyos de la prensa británica". Revista internacional de Historia de la Comunicación, 4 (2015): 52-74. https://idus.us.es/handle/11441/78586

Instituto de Opinión Pública. "Cuestiones de actualidad. Estudio 1046". Madrid: Centro de Investigaciones Sociológicas, 1971a.

--. "Cuestiones de actualidad. Estudio 1050". Madrid: Centro de Investigaciones Sociológicas, $1971 \mathrm{~b}$.

--. "Encuesta sobre turismo interior y temas políticos. Estudio 1060". Madrid: Centro de Investigaciones Sociológicas, 1972.

Lemus, Encarnación (2008). "Los Estados Unidos y la imagen de la situación española en vísperas de la Transición política". Historia del presente, 11 (2008): 97-110. http://historiadelpresente.es/sites/default/files/revista/articulos/11/11.5encarnacio nlemuslosestadosunidosylaimagendelasituacionespanolaenvisperasdelatransicion politica.pdf

Martínez, Guillem (coord.). CT o la cultura de la transición. Madrid: Debolsillo, 2016.

Magallón-Rosa, Raúl. "Datos abiertos y acceso a la información pública en la reconstrucción de la historia digital". Historia y comunicación social, 22, 2 (2017): 297-308. doi: https://doi.org/10.5209/HICS.57845

--. "The forbidden opinion polls of the Spanish Transition. Access to public information and digital history". Cultural and Digital History Journal, 7, 2. (2018): doi: https://doi.org/10.3989/chdj.2018.019

Miquel, Jorge. "La transición a la democracia y la aceptación de la Monarquía española". Red para el Estudio de las Monarquías Contemporáneas, (2017) https://remco.es/la-transicion-la-democracia-la-aceptacion-la-monarquiaespanola/

Ortí, Alfonso. "Transición postfranquista a la monarquía parlamentaria y relaciones de clase: del desencanto programado a la socialtecnocracia transnacional”. Política $\begin{array}{llll}y & \text { sociedad, } & 2 & \text { (1989): }\end{array}$ https://dialnet.unirioja.es/servlet/articulo?codigo $=154297$

Paula, Naftalí. La representación de la nueva imagen de la Casa Real Española: de Juan Carlos I a Felipe VI. Tesis Doctoral. Madrid: UC3M, 2019. 
Payne, Stanley. “¿Tardofranquismo o pretransición?”. Documentos de Trabajo. Cuadernos de la España Contemporánea, 2, 1 (2007). http://personal.us.es/clanga/uploads/payne tardofranquismo.pdf

Ramos, Fernando. "Los escándalos de la Corona española en la prensa digital y el futuro de la monarquía: de la amnesia y el silencio cómplice al tratamiento exhaustivo en los medios". Razón y Palabra, 17, 79 (2012). http://ww35.razonypalabra.org.mx/N/N79/V79/71_Ramos_V79.pdf

--. "El «tabú» periodístico de la monarquía en España: la crisis real y la crisis coyuntural". Revista Latina de Comunicación Social, 68 (2012): 217-247. http://www.revistalatinacs.org/068/paper/975 Vigo/09 Ramos.html

Ridao, Joan. "Abdicación y monarquía parlamentaria en la España del siglo XXI". $\begin{array}{llllll}\text { Derecho } y \quad \text { Cambio } & \text { Social, 11, } 37 \text { (2014): }\end{array}$ https://dialnet.unirioja.es/servlet/articulo?codigo $=4750224$

Rueda, José Carlos. "Entre Franco y Juan Carlos. Representación y memoria en televisión y otros medios populares (1966-1975)". Historia Actual Online, 32 (2013): 93-105. https://dialnet.unirioja.es/servlet/articulo?codigo $=4452382$

Sánchez-Duarte, José Manuel y Magallón-Rosa, Raúl. "Desafíos en la publicación de encuestas electorales. La relación entre empresas demoscópicas y medios de comunicación". Signo y Pensamiento, 37 (2019): 70-84. doi: https://doi.org/10.11144/Javeriana.syp37-73.dpee

Sánchez-Prieto, Juan María. "La Transición o la recuperación de una España Posible". Studia historica. Historia contemporánea, 12 (1994): 173-190.

Seco, C. "La monarquía, clave de la transición". Cuenta y razón, (1995): 12-20. https://dialnet.unirioja.es/servlet/articulo?codigo $=70915$

Velasco, Ana María. "Monarquía y medios de comunicación: de la Transición a Corinna zu Sayn-Wittgenstein”. Observatorio $\left(O B S^{*}\right), 12,3$ (2019): 122-137. doi: http://dx.doi.org/10.15847/obsOBS12320181203

Zugasti, Ricardo (2005). "La legitimidad franquista de la Monarquía de Juan Carlos I: un ejercicio de amnesia periodística durante la transición española". Comunicación y sociedad, vol. XVIII, 2 (2005): 141-168. http://dadun.unav.edu/bitstream/10171/8252/1/20090701091133.pdf

Zugasti, Ricardo. "Juan Carlos I y el acercamiento a Europa en la prensa española de la transición (1975-1977)". Comunicación y Hombre, 3 (2007a): 108-123. http://ddfv.ufv.es/handle/10641/830

--. "La prensa de la transición como escenario de apoyo político a Juan Carlos I: el ejemplo de la legitimidad dinástica de la monarquía". Palabra Clave, 10, 1 (2007b): 60-71. http://www.redalyc.org/html/649/64910105/

-- . "El viaje de la reconciliación: la prensa española ante la primera visita oficial de Juan Carlos I a México”. Espacios Públicos, 11, 21 (2008): 338-351.

--. "Esperando el nombramiento de Juan Carlos de Borbón: la cuestión monárquica en la prensa española (1968-1969)". Comunicación y pluralismo, 8 (2009): 181194. https://dialnet.unirioja.es/servlet/articulo?codigo $=3151427$ 